\title{
Composites Bond Inspection Using Heterodyne Effect and SuRE Methods
}

\author{
Shervin Tashakori $\mathbb{D}^{1},{ }^{1}$ Amin Baghalian, ${ }^{1}$ Volkan Y. Senyurek, ${ }^{1}$ Saman Farhangdoust $\mathbb{D},{ }^{2}$ \\ Dwayne McDaniel, ${ }^{3}$ and Ibrahim N. Tansel ${ }^{1}$ \\ ${ }^{1}$ Department of Mechanical and Materials Engineering, Florida International University, Miami, FL, USA \\ ${ }^{2}$ Department of Civil and Environmental Engineering, Florida International University, Miami, FL, USA \\ ${ }^{3}$ Applied Research Center, Florida International University, Miami, FL, USA
}

Correspondence should be addressed to Shervin Tashakori; stash002@fiu.edu

Received 10 April 2018; Accepted 3 July 2018; Published 19 July 2018

Academic Editor: Luca Z. Fragonara

Copyright (c) 2018 Shervin Tashakori et al. This is an open access article distributed under the Creative Commons Attribution License, which permits unrestricted use, distribution, and reproduction in any medium, provided the original work is properly cited.

\begin{abstract}
With increasing utilization of the composite materials in commercial and military applications, the longevity of composite bonds has become a crucial concern of the aerospace industry. In spite of the previous studies in the literature for characterization of bonding condition in composite materials, implementation of more advanced structural health monitoring (SHM) techniques are still required to ensure flight safety and quick inspections of structures. In this study, two different SHM methods were used to evaluate the strength of composite bonds by using two separate experimental setups. First, the heterodyne effect method was used for assessing the separation in the composite joint. Then, the surface response to excitation (SuRE) method was used for studying various simulated contamination levels. Results of the experimental studies showed that the proposed methods could be efficiently utilized for evaluating bonding strength of composite materials.
\end{abstract}

\section{Introduction}

Composite materials have found numerous applications in automotive, industrial, aerospace, civil, and mechanical engineering applications due to their excellent strength to weight ratio and resistance to corrosion [1-5]. Particularly, Carbon Fiber Reinforced Plastics (CFRPs) have been widely used in the aerospace industry because of these benefits. Investigation of the longevity of the composite materials is of great importance in these critical applications [6-8]. Two important areas of concern regarding the usage of the composite materials are delamination and debonding of composite joints. Debonding and delamination would severely reduce the strength of the composite structures and may lead to catastrophic failures $[9,10]$.

Nondestructive testing (NDT) methods were proposed for inspection of different Engineering applications by Farhangdoust et al. $[11,12]$ and composite materials during their service lives by Bayraktar et al. [13]. Application of various NDT methods, such as visual testing (VT or VI), ultrasonic testing (UT), thermography, radiographic testing (RT), electromagnetic testing (ET), acoustic emission (AE), and shearography testing in the evaluation of composite bonds, has been reviewed by Gholizadeh [14]. Boopathy et al. [2] discussed the merits of the NDT methods for inspecting the composite structures of the aircraft. Two approaches have been developed to detect various types of bond damages in composites by considering the surface or internal defects $[14,15]$. Detection of the defects of the composite structures by using piezoceramic sensors has been studied by Staszewski et al. [16]. Structural health monitoring (SHM) methods were implemented for online monitoring of composite structures [16-21]. Two inspection methods for the composite bond were analyzed by Crane and Dillingham [22]. They included a brief review of inspection methods for the adhesive bonds. Lissenden and 
Rose [23] embedded piezoelectric fibers into the composite materials and experimentally evaluated their performance. Sensor-embedded composite structures have great potential for implementation in military applications.

When pinching, harmonic excitation is applied to the surfaces of the well manufactured composite planes; the surface waves primarily propagate with the applied frequencies. This behavior is considered linear. Particular types of damages, such as debonding and delamination, can cause the structure to change its behavior from a linear to a nonlinear state. The propagating surface waves will have additional frequencies. When these structures with these types of nonlinear behavior are excited with two appropriate excitation frequencies, the new frequencies appear in the response of the system at the difference, summation, and some other harmonics of the two excitation frequencies. This phenomenon is known as the heterodyne effect [24, 25]. The heterodyne method uses relatively low voltage excitation signal in comparison to the other nonlinear SHM methods [26-29], and the excitation frequencies are not limited to the combination of a high and a low frequency.

Electromechanical Impedance (EMI) method is one of the most popular linear SHM methods. Surface response to excitation (SuRE) method is the cheaper alternative of the EMI approach and gives the user the freedom for selection of the sensor and the location of the monitored response [30-36]. The SuRE method detects the developing structural defects by monitoring the variation of the frequency response of the structure when it is excited by using a sweep sine wave in a broad frequency range.

In this study, heterodyne and SuRE methods are used for inspection of the bonds of composite joints. The goal was a comparison of the performances of nonlinear and linear approaches. In the following sections, the theoretical background, experimental methods, results, and conclusion are presented.

\section{Theoretical Background}

The heterodyne and SuRE methods will be briefly discussed in this section.

2.1. Heterodyne Method. The heterodyne method was originally developed for radio transmission; however, it has been used in many other applications. Typically, the input and the output frequencies of linear systems are the same. However, nonlinear systems create additional frequencies. When some nonlinear systems are excited at two different frequencies, their behaviors are very predictable. They generate new frequencies at the difference, addition, and some other harmonics of the excitation frequencies. This is called the heterodyne effect. The heterodyne method monitors the development of these new frequencies in the signal. Since the characteristics of the system change from linear to nonlinear with the development of the defects, it is not necessary to get baseline or reference in pristine conditions and to quantify the difference of these characteristics with the time.
2.2. Surface Response to Excitation (SuRE) Method. SuRE method uses a piezoelectric transducer to excite the structure in a wide frequency range. The response of the system is monitored at the desired location with another piezoelectric sensor. The frequency spectrum of the response is calculated. The frequency spectrum is consistent if there are no changes in the structure. By the development of any defects such as a crack or delamination, the frequency spectrum changes.

The frequency response of the monitored signal is collected when the structure is in the desired condition. This is considered the reference or baseline. The frequency response of the system was periodically obtained, and the sum of the squared differences (SSD) between the baseline and collected data is calculated by the following equation:

$$
\mathrm{SSD}=\sum_{i=1}^{m}\left|B_{m \times 1}-R_{m \times 1}\right|^{2}
$$

In this equation, $B$ and $R$ are the amplitudes of the FFT for the baseline and periodically collected data another time and $m$ represents the number of frequencies for the FFT.

\section{Experimental Setup}

To evaluate the performances of the heterodyne effect and the SuRE method, contamination between two plates was simulated. Two square carbon fiber composite plates with $11.75^{\prime \prime} \times 11.75^{\prime \prime} \times 0.06^{\prime \prime}$ dimensions were held together by using four nickel-plated magnet pairs each with $1^{\prime \prime}$ diameter and $3 / 8^{\prime \prime}$ thickness. Aluminum foils were used to act like simulated contamination or debonding.

3.1. Heterodyne Method. For evaluating the performance of the heterodyne method, two PZT disks with the distance of 6 " were attached to the top plate to excite the system with two harmonic waves with different frequencies. Another PZT disk was attached to the center of the bottom plate to act as the sensor. Three different sizes of aluminum foils were used to act as the contaminant by separating the composite plates. The diameter and the thickness of the PZT disks were $0.8^{\prime \prime}$ and $0.04^{\prime \prime}$, respectively. The signals of the PZT disk located at the center were recorded at $1 \mathrm{MHz}$ sampling rate.

3.2. Surface Response to Excitation (SuRE) Method. To evaluate the performance of the SuRE method, the same plates with two PZTs attached to the top plate were used. One of them was used as an exciter and the other one was used as the sensor. The exciter was used to create surface waves at the surface of the structure in the broad range of frequencies by using sweep sine wave. The diameter and the thickness of the PZT disks were $0.8^{\prime \prime}$ and $0.04^{\prime \prime}$, respectively. The signal of the PZT disk which was used as a sensor was recorded at a $1 \mathrm{MHz}$ sampling rate.

\section{Results and Discussion}

Two sets of experiments were performed to detect the size of simulated contamination between two composite plates 


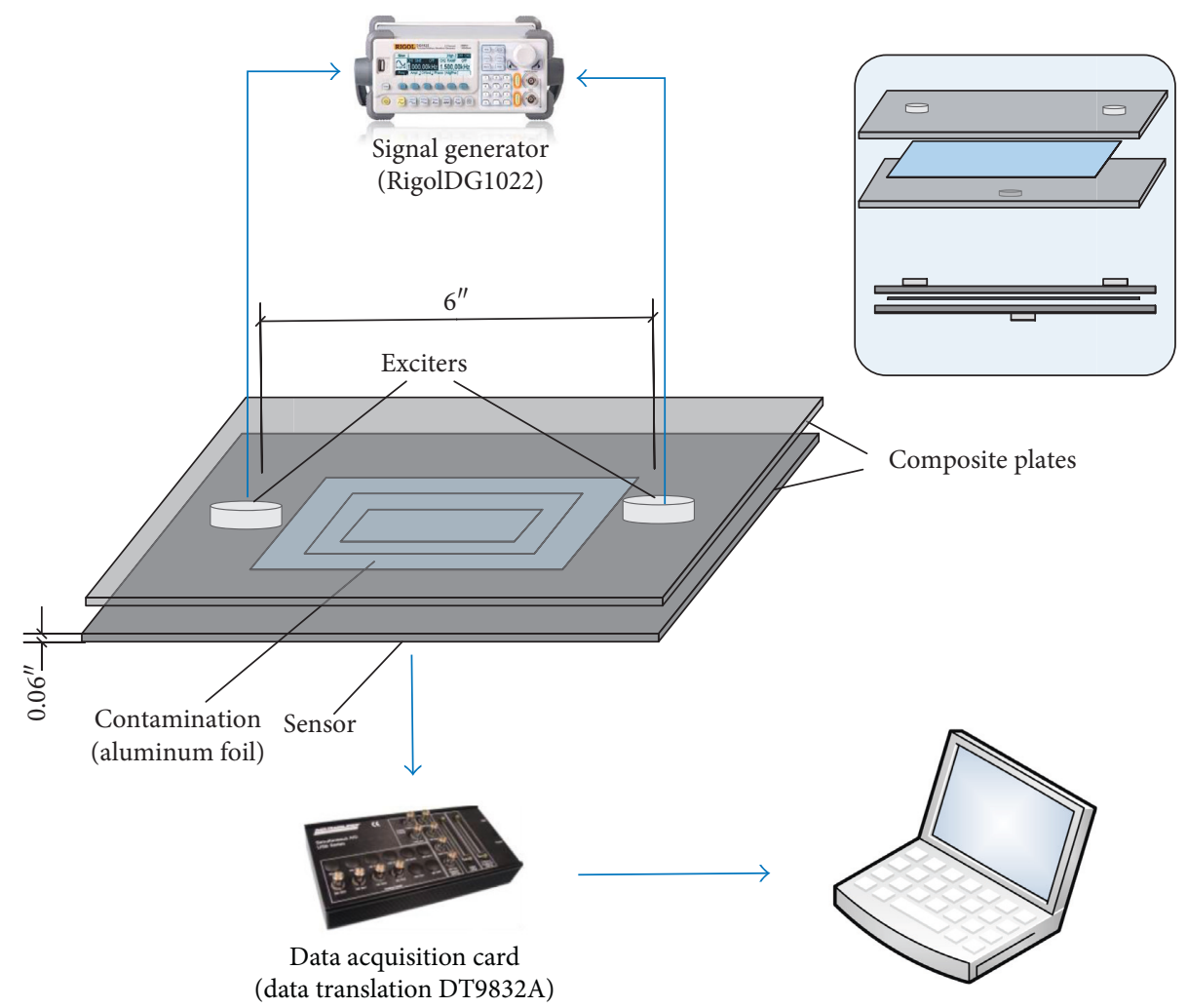

FiguRE 1: Diagram of the bond inspection setup to evaluate the performance of the heterodyne effect.

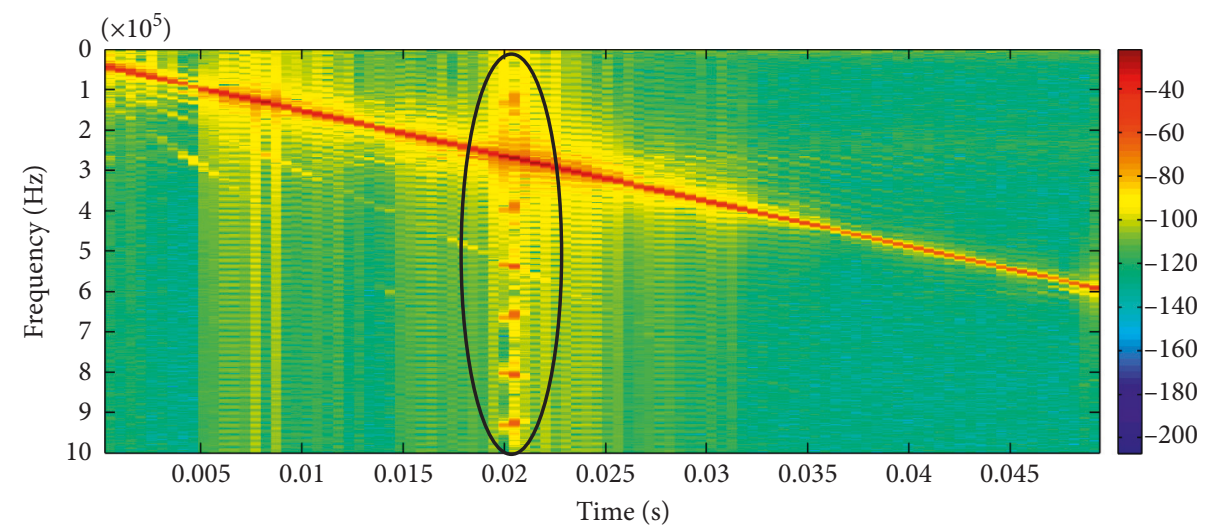

FigURE 2: Time-frequency spectrum to determine optimum excitation frequency.

when composite plates were held together using magnet pairs. In the course of the experiment, it was shown that heterodyne effect and SuRE method can efficiently detect the simulated contaminations in the composite bonds as nonlinear and linear SHM methods, respectively.

4.1. Heterodyne Method. The experimental setup shown in Figure 1 was used to evaluate the effect of different levels of contamination between the plates. First, practical test frequencies were selected for the experiments. Later, the best frequency combination was used when different foil sizes were sandwiched between the plates. The amplitude of the frequency at the difference of the excitation frequencies was monitored.

In the experiments, three different sizes of aluminum foil sheets were sandwiched between the composite plates. The plates were held together with four couples of magnets. The experimental setup shown in Figure 1 was used. The PZT on the top plate was excited with a sweep sine wave from $50 \mathrm{kHz}$ to $550 \mathrm{kHz}$. The spectrogram of the PZT signal at the bottom is presented in Figure 2. The structure showed the significant nonlinear behavior around $250 \mathrm{kHz}$. This frequency and two other frequencies with $20 \mathrm{kHz}$ difference, $230 \mathrm{kHz}$ and $270 \mathrm{kHz}$, were selected as the excitation signal for the next step. 


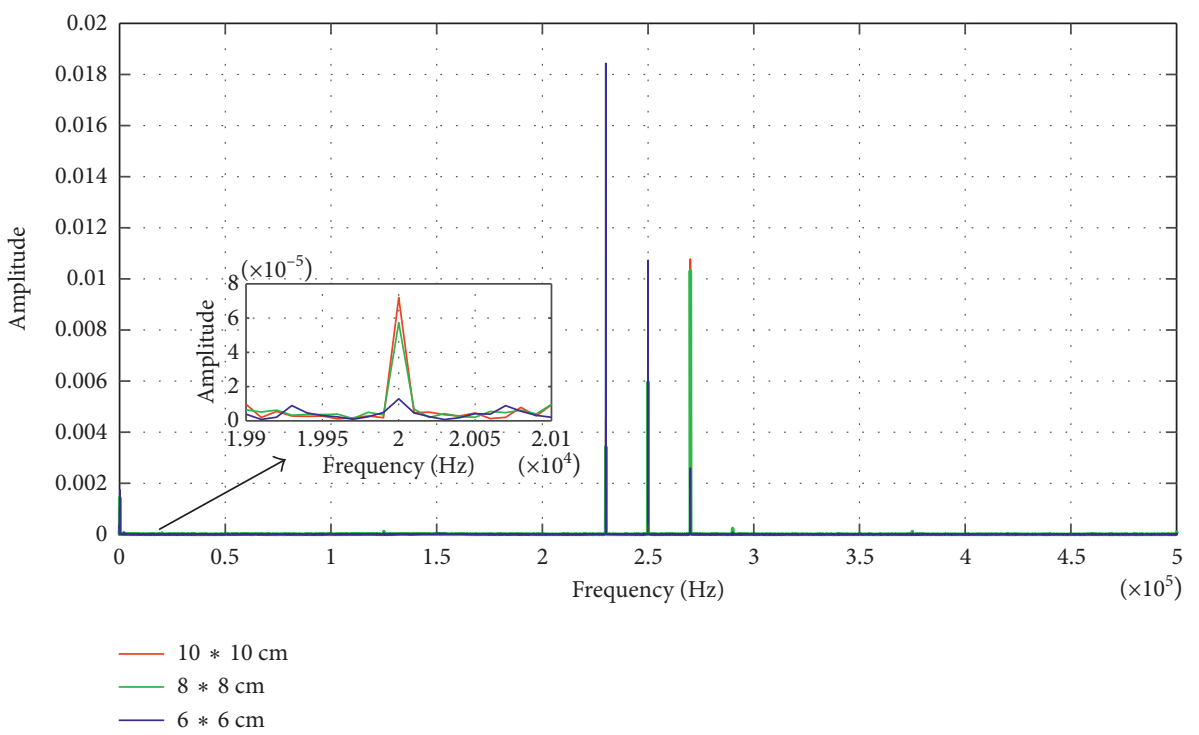

FIGURE 3: Comparing FFT results between different levels of simulated contamination in the heterodyne method.

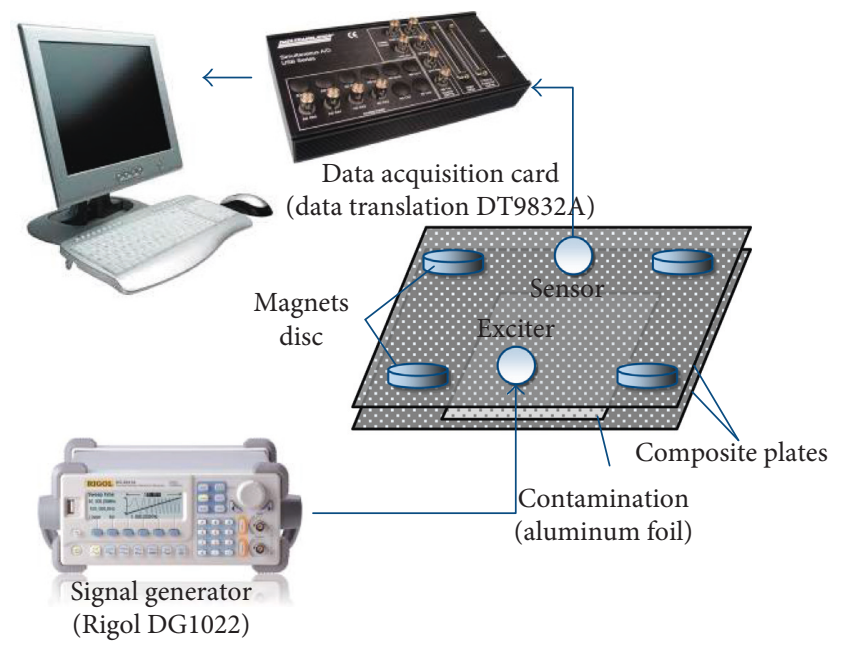

FIGURE 4: Schematic of the bond inspection in composite plates using the SuRE method.

In this step, two PZTs on the top plate were excited with $230 \mathrm{kHz}, 250 \mathrm{kHz}$, and $270 \mathrm{kHz}$ using $20 \mathrm{~V}$ peak to peak voltage for excitation frequencies. One of the PZTs was excited using the combination of all three, $230 \mathrm{kHz}$, $250 \mathrm{kHz}$, and $270 \mathrm{kHz}$, frequencies when another PZT only used $250 \mathrm{kHz}$. The PZT attached to the bottom plate recorded the response signal with $1 \mathrm{MHz}$ sampling frequency. The spectrum was calculated when the experiment was repeated by three different size foils simulating varying degrees of the simulated contamination. First, the $6^{\prime \prime}$ by $6^{\prime \prime}$ aluminum foil was used for separation of the top and bottom composite plates. Later, the experiment was repeated when the $8^{\prime \prime}$ by $8^{\prime \prime}$ and $10^{\prime \prime}$ by $10^{\prime \prime}$ aluminum foils were utilized. The spectrum of the signals of the PZT which was attached to the bottom plate was calculated by using FFT and is presented in Figure 3. In this plot, the spikes around three excitation frequencies $(230 \mathrm{kHz}, 250 \mathrm{kHz}$, and $270 \mathrm{kHz}$ ) can be seen. By zooming in on the difference of

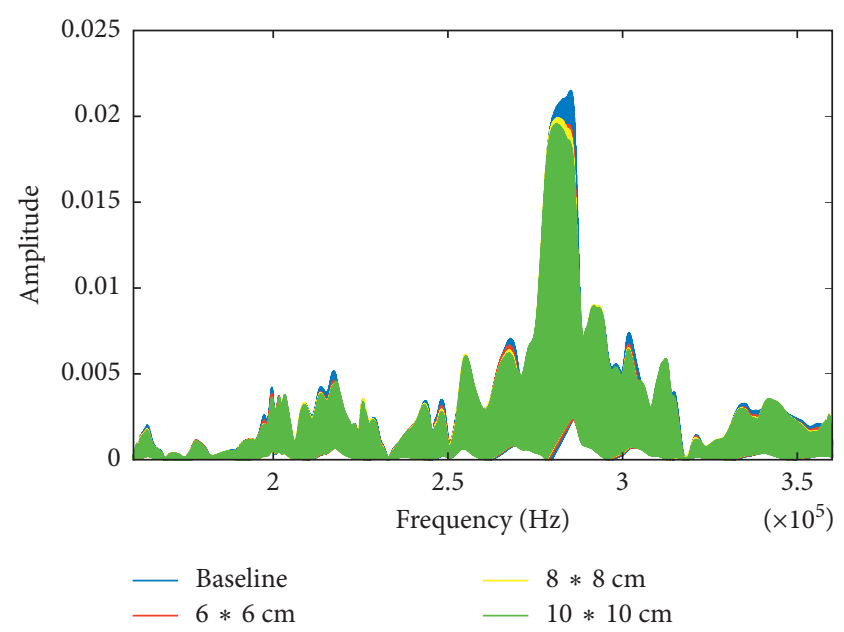

FIgURE 5: Comparing the spectrums obtained from four different experiments to evaluate the performance of the SuRE method.

the excitation frequencies, $20 \mathrm{kHz}$, it can be seen that the amplitudes of the spike increased when the separated area between the composite plates was increased (Figure 3).

4.2. Surface Response to Excitation (SuRE) Method. The experimental setup shown in Figure 4 was used. A sweep sine wave from $10 \mathrm{kHz}$ to $370 \mathrm{kHz}$ was applied to the PZT on the top plate (Figure 5). The other PZT at the bottom plate was used as the sensor. The baseline data were collected when the composite plates were held together without any aluminum foil between them. The spectrum of the signal was calculated by using the FFT. The experiment was repeated three times with the different sizes of aluminum foil were sandwiched between the plates. The spectrums collected at the four tests are presented in Figure 5. Experiments were performed without any foil, and three different sizes of foils were sandwiched between the plates. 


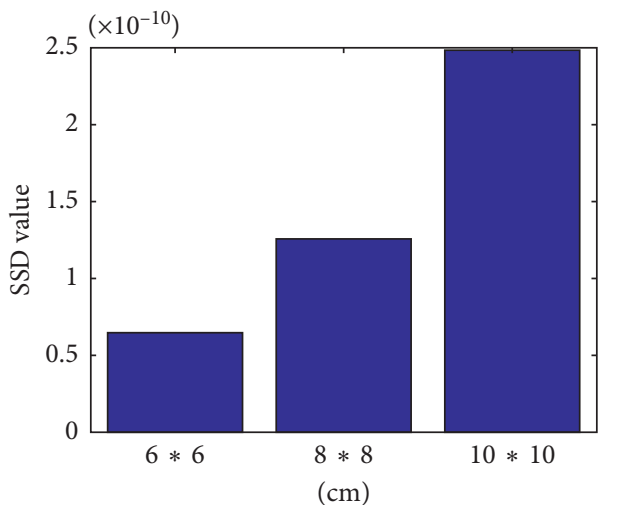

FIGURE 6: SSD results at different levels of simulated contamination.

The SSD increased when the size of the simulated contamination between two composite plates increased (Figure 6). The results indicated that the SuRE method can be used for detection of simulated contamination between the plates.

\section{Conclusions}

Composite materials are joined together with adhesives in many applications. Several SHM methods have been developed for detection of weak bonding and delamination which can lead to failure. In this study, performances of the heterodyne and SuRE methods were compared. Heterodyne method evaluated the change of the behavior of the structure from linear to nonlinear. The SuRE method assessed the change of the response characteristics or linear behavior.

First, the heterodyne method was used to identify the change in the size of the simulated contamination between two composite plates. First, a sweep sine wave was used to recognize the proper excitation frequencies for the heterodyne method. Since there was nonlinearity in the system, new frequencies at the difference, summation, and some other harmonics of the two excitation frequencies appeared. By monitoring the amplitude of the spike at the difference frequency, it was shown that the amplitude of the spike increased by the increase of the simulated contamination size between two composite plates.

Secondly, the surface response to excitation (SuRE) method was used for the detection of simulated contamination between two composite plates with a linear SHM method. A PZT attached to the top plate was used to excite the surface of the top composite plate at a broad frequency range. Second PZT on the same plate was used to monitor the surface waves. The SSD increased with the increase of the size of the simulated contamination between the two composite plates. The SSD index was reasonably sensitive to the changes of the simulated contamination size.

Based on the results, the use of both methods is feasible for detecting separation between the joined composite plates with sturdy fasteners or adhesives. The SuRE method was more sensitive to the simulated contamination and size of it. However, it requires a baseline or reference data. The heterodyne effect also worked well without any baseline.
Typically, we cannot expect the increase in the amplitude of the spike at the difference of the excitation frequencies by the length of the contamination since the amplitude of the spike depends on the effective length of the rubbing surfaces, not the nominal length of the contamination. In this case, the size of the rubbing surface was carefully increased while sandwiching the aluminum foils. Also, it would be possible to locate the delamination in the heterodyne method using neural network approaches, by looking at the amplitude of the spikes at different combinations of excitation frequencies.

\section{Data Availability}

The time and frequency domain data used to support the findings of this study were collected by Shervin Tashakori. Requests for access to these data should be made to Shervin Tashakori at Florida International University.

\section{Conflicts of Interest}

The authors declare that they have no conflicts of interest.

\section{References}

[1] A. A. Hassen, H. Taheri, and U. K. Vaidya, "Non-destructive investigation of thermoplastic reinforced composites," Composites Part B: Engineering, vol. 97, pp. 244-254, 2016.

[2] G. Boopathy, G. Surendar, A. Nema, and T. P. P. Anand, "Review on non-destructive testing of composite materials in aircraft applications," International Journal of Mechanical Engineering \& Technology, vol. 8, no. 8, pp. 1334-1342, 2017.

[3] B. Uy, "Modern design, construction and maintenance of composite steel-concrete structures: Australian experiences," Electronic Journal of Structural Engineering, 1st International Conference on Modern Design, Construction and Maintenance of Structures, pp. 42-48, Hanoi, Vietnam, December 2007.

[4] Z. B. Zabinsky, M. E. Tuttle, and C. Khompatraporn, "A case study: composite structure design optimization," Journal of Global Optimization, vol. 85, pp. 507-528, 2006.

[5] C. J. Lissenden and J. Rose, "Structural health monitoring of composite laminates through ultrasonic guided wave beam forming," in NATO Applied Vehicle Technology, pp. 1-14, Pennsylvania State University, University Park, PA, USA, 2008.

[6] K. B. Katnam, L. F. M. Da Silva, and T. M. Young, "Bonded repair of composite aircraft structures: a review of scientific challenges and opportunities," Progress in Aerospace Sciences, vol. 61, pp. 26-42, 2013.

[7] D. Vértesy, "A critical assessment of quality and validity of composite indicators of innovation," in Proceedings of the OECD Blue Sky Forum on Science and Innovation Indicators, pp. 1-20, Ottawa, ON, Canada, 2016.

[8] G. Georgeson, "Trends in R\&D for nondestructive evaluation of in-service aircraft," in Proceedings of the 5th International Symposium on NDT in Aerospace, pp. 13-15, Singapore, November 2013.

[9] A. Raimondo and A. Riccio, "Inter-laminar and intra-laminar damage evolution in composite plates with skin-stringer debonding under compression," Composites Part B: Engineering, vol. 94, pp. 139-151, 2016. 
[10] P. K. Majumdar, M. Y. Bhuiyan, J. Clifford, F. H. Haider, and K. L. Reifsnider, "Multi-physical description of material state change in composite materials," in SAMPE Conference Proceedings, pp. 1-11, Society for the Advancement of Material and Process Engineering, Baltimore, MD, USA, May 2015.

[11] S. Farhangdoust, A. B. Mehrabi, and S. F. A. Mowsavi, "NDT methods applicable to health monitoring of ABC closure joints," in Proceedings of the 27th Research Symposium-The American Society for Non-Destructive Testing (ASNT), Orlando, FL, USA, March 2018.

[12] A. B. Mehrabi and S. Farhangdoust, "A laser-based noncontact vibration technique for health monitoring of structural cables: background, success, and new developments," Advances in Acoustics and Vibration, vol. 2018, pp. 1-13, 2018.

[13] E. Bayraktar, S. D. Antolovich, and C. Bathias, "New developments in non-destructive controls of the composite materials and applications in manufacturing engineering," Journal of Materials Processing Technology, vol. 206, no. 1-3, pp. 30-44, 2008.

[14] S. Gholizadeh, "A review of non-destructive testing methods of composite materials," Procedia Structural Integrity, vol. 1, pp. 50-57, 2016.

[15] L. Greve and A. K. Pickett, "Modelling damage and failure in carbon/epoxy non-crimp fabric composites including effects of fabric pre-shear," Composites Part A: Applied Science and Manufacturing, vol. 37, no. 11, pp. 1983-2001, 2006.

[16] W. J. Staszewski, S. Mahzan, and R. Traynor, "Health monitoring of aerospace composite structures-active and passive approach," Composites Science and Technology, vol. 69, no. 1112, pp. 1678-1685, 2009.

[17] R. L. Rito, A. D. Crocombe, and S. L. Ogin, "Health monitoring of composite patch repairs using CFBG sensors: experimental study and numerical modelling," Composites Part A: Applied Science and Manufacturing, vol. 100, pp. 255-268, 2017.

[18] R. Jones and S. Galea, "Health monitoring of composite repairs and joints using optical fibres," Composite Structures, vol. 58, no. 3, pp. 397-403, 2002.

[19] W. Roth and V. Giurgiutiu, "Structural health monitoring of an adhesive disbond through electromechanical impedance spectroscopy," International Journal of Adhesion and Adhesives, vol. 73, pp. 109-117, 2017.

[20] K. I. Salas and C. E. S. Cesnik, "Guided wave structural health monitoring using CLoVER transducers in composite materials," Smart Materials and Structures, vol. 19, no. 1, p. 15014, 2010.

[21] P. Kudela, W. Ostachowicz, and A. Żak, "Damage detection in composite plates with embedded PZT transducers," $M e$ chanical Systems and Signal Processing, vol. 22, no. 6, pp. 1327-1335, 2008.

[22] R. L. Crane and G. Dillingham, "Composite bond inspection," Journal of Materials Science, vol. 43, no. 20, pp. 6682-6694, 2008.

[23] C. Lissenden and J. Rose, "Structural health monitoring of composite laminates through ultrasonic guided wave beam forming," NATO Applied Vehicle Technology, pp. 1-14, Pennsylvania State University, University Park, PA, USA, 2008.

[24] A. Baghalian, V. Y. Senyurek, S. Tashakori, D. McDaniel, and I. N. Tansel, "A novel nonlinear acoustic health monitoring approach for detecting loose bolts," Journal of Nondestructive Evaluation, vol. 37, no. 2, p. 24, 2018.
[25] S. Tashakori, A. Baghalian, V. Y. Senyurek, M. Unal, D. McDaniel, and I. N. Tansel, "Implementation of heterodyne effect for monitoring the health of adhesively bonded and fastened composite joints," Applied Ocean Research, vol. 72, pp. 51-59, 2018.

[26] S. Farhangdoust, D. Younesian, and E. Esmailzadeh, "Interaction of higher modes in nonlinear free vibration of stiffened rectangular plates," in Proceedings of the 29th Conference on Mechanical Vibration and Noise, vol. 8, Cleveland, OH, USA, August 2017.

[27] K. E.-A. Van Den Abeele, J. Carmeliet, J. A. Ten Cate, and P. A. Johnson, "Nonlinear elastic wave spectroscopy (NEWS) techniques to discern material damage, part II: single-mode nonlinear resonance acoustic spectroscopy," Research in Nondestructive Evaluation, vol. 12, no. 1, pp. 31-42, 2000.

[28] T. J. Ulrich, M. Remillieux, P.-Y. Le Bas, and C. Payan, "Multimode nonlinear resonant ultrasound spectroscopy (NRUS): from one-dimensional to three-dimensional characterization of the hysteretic elastic nonlinearity," Journal of the Acoustical Society of America, vol. 138, no. 3, p. 1886, 2015.

[29] A. Hosseinkhani, D. Younesian, and S. Farhangdoust, "Dynamic analysis of a plate on the generalized foundation with fractional damping subjected to random excitation," Mathematical Problems in Engineering, vol. 2018, pp. 1-10, 2018.

[30] A. Baghalian, S. Tashakori, H. Fekrmandi et al., Implementation of the Surface Response to Excitation Method for Pipes, Springer International Publishing, Basel, Switzerland, 2017.

[31] S. Tashakori, A. Baghalian, M. Unal et al., Load Monitoring Using Surface Response to Excitation Method, Springer International Publishing, Basel, Switzerland, 2017.

[32] A. Baghalian, S. Tashakori, J. R. Soto, V. Y. Senyurek, I. N. Tansel, and B. Uragun, "Internal defect detection in hollow cylindrical structures using the Surface Response to Excitation (SuRE) Method," in Proceedings of the 2017 8th International Conference on Recent Advances in Space Technologies (RAST), pp. 523-527, İstanbul, Turkey, June 2017.

[33] S. Tashakori, A. Baghalian, J. Cuervo, V. Y. Senyurek, I. N. Tansel, and B. Uragun, "Inspection of the machined features created at the embedded sensor aluminum plates," in Proceedings of the 2017 8th International Conference on Recent Advances in Space Technologies (RAST), pp. 517-522, İstanbul, Turkey, June 2017.

[34] H. Fekrmandi, M. Unal, A. Baghalian et al., "A non-contact method for part-based process performance monitoring in end milling operations," International Journal of Advanced Manufacturing Technology, vol. 83, no. 1-4, pp. 13-20, 2015.

[35] A. Baghalian, S. Tashakori, V. Y. Senyurek, D. Mcdaniel, H. Fekrmandi, and I. N. Tansel, "Non-contact quantification of longitudinal and circumferential defects in pipes using the surface response to excitation (SuRE) method," International Journal of Prognostics and Health Management, pp. 21532648, 2017.

[36] S. Tashakori, A. Baghalian, M. Unal et al., "Contact and noncontact approaches in load monitoring applications using surface response to excitation method," Measurement, vol. 89, pp. 197-203, 2016. 


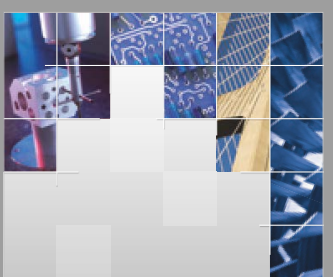

\section{Enfincering}
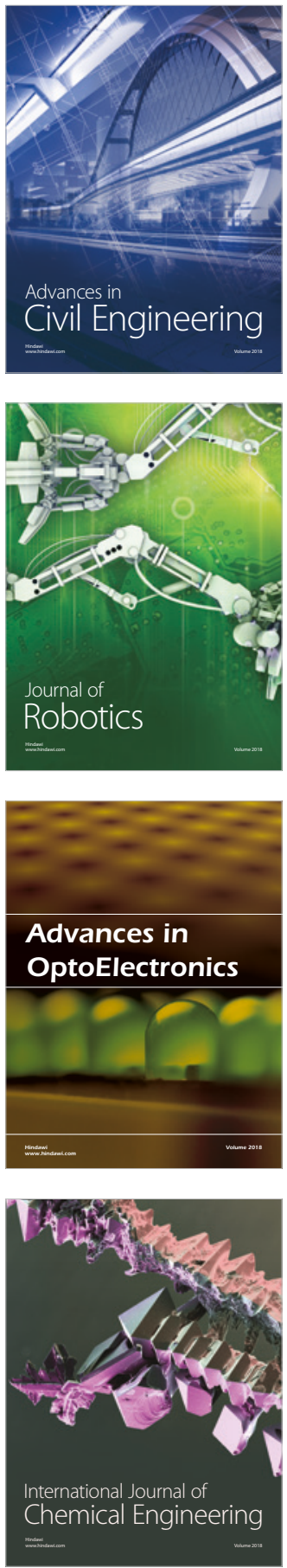

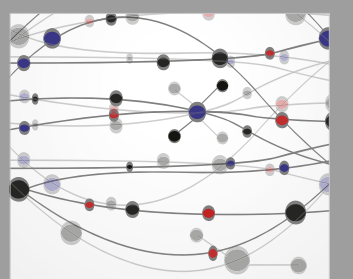

\section{Rotating \\ Machinery}

The Scientific World Journal

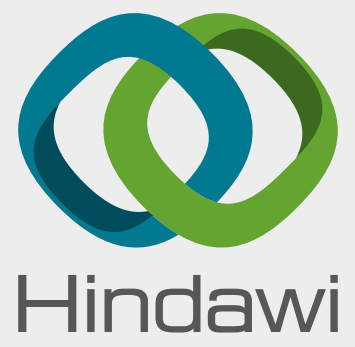

Submit your manuscripts at

www.hindawi.com
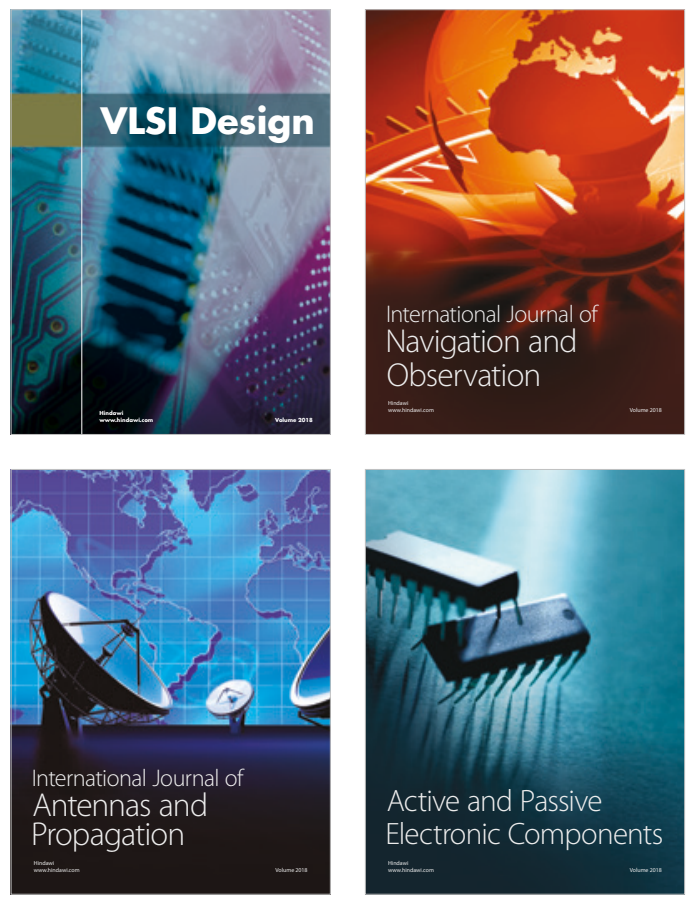
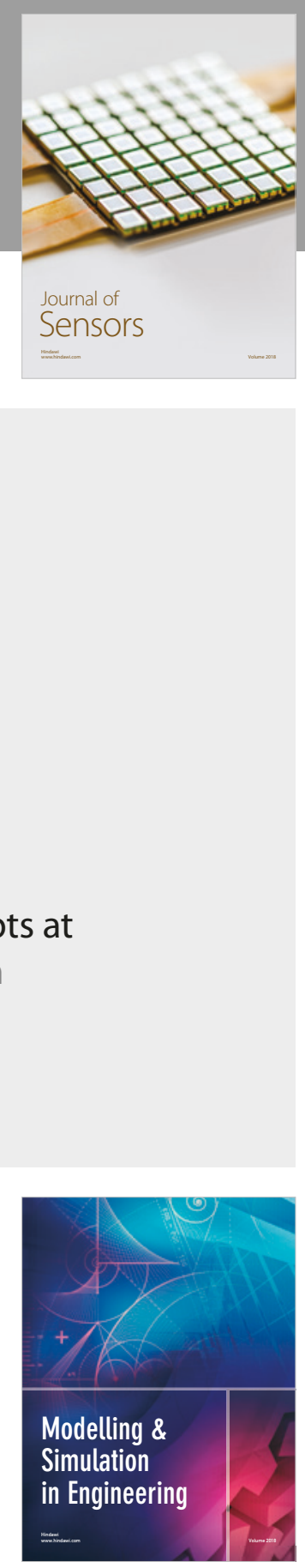

\section{Advances \\ Multimedia}
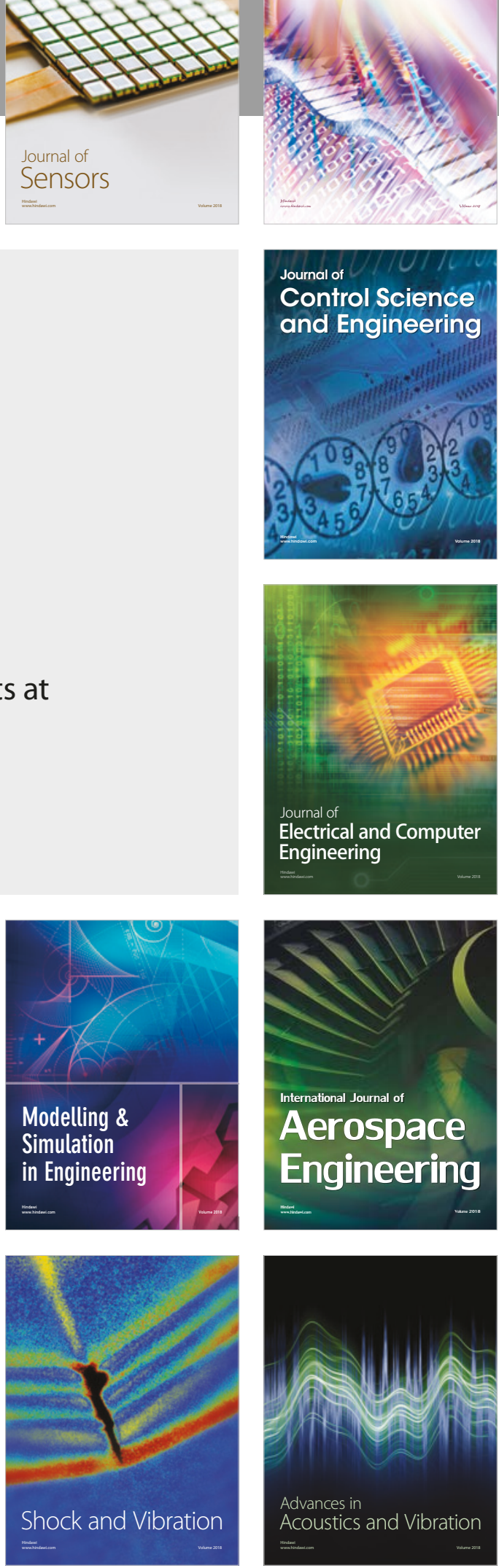